\title{
COVID-19 impact on air quality and associated elements: knowledge data of the Emirate of Ajman - UAE
}

\author{
Yaser Omar Kaied*, Abdul Salam K. Darwish, and Peter Farrell \\ School of Civil Engineering, University of Bolton, UK
}

Received: 15 March 2021 / Received in final form: 21 March 2021 / Accepted: 22 March 2021

\begin{abstract}
Air pollution is one of the core issues at the local and global levels and maybe "one of the most important contributors" to deaths. According to the United Nations, air pollution is one of the extreme environmental threats to health globally. Air pollution problems increased worldwide due to the massive emission volumes generated every day from the increased lifestyle associated technology. The air pollutants are not only dangerous to the health and wellbeing of plants, animals, and people, but they are also harmful to the environment as a significant contributor to recent climate change. The reduction in the volume of pollutants produced is a crucial and challenging step in managing our adverse effects on the environment and climate. The primary outdoor pollution sources include vehicles, Industry, power generation, building heating/cooling systems, and agriculture/waste incineration. The regulation, policies, clean production, investments supporting cleaner transport, energy-efficient housing, power generation, Industry, and better municipal waste management can effectively reduce critical sources of ambient air pollution. When many countries of the world are fighting the Coronavirus, as a challenge to limit its spread, because of its negative repercussions on the economy, health, and political stability as well, several reports have emerged confirming that the spread of the virus has positive effects on the climate change crisis through its impact on the demand for energy and greenhouse gas emissions in endemic countries. Ajman is an emirate that has experienced considerable change in the level of air-associated pollution. Therefore, this article aims to assess air quality impacts in the Ajman Emirates during the lockdown when social distancing was implemented, and human activities were significantly eliminated. Moreover, it seeks to identify the percentages of the improved outdoor pollutants concentrations and the general air quality index. This paper shows evidence from live measurements that the Emirate has recorded over four months since the lockdown was imposed at this Emirate and compared with similar months of the previous year. Moreover, it indicates that having climate improvement exists for specific periods could well support the fight against the COVID-19. The article clearly shows results with a significant reduction of more than $40 \%$ of each air-associated pollution element during the pandemic compared with similar periods in 2018 and 2019 .
\end{abstract}

\section{Introduction}

Climate change and air pollution must turn out to be one of the greatest essential and severe global crises that the international community suffers from because it has impacts on all aspects of life, including health, especially on the spread of infectious diseases through changes in environmental and biological factors, as it affects rainfall patterns, floods, droughts, water shortages. Studies have shown that climate changes directly or indirectly affect the transmission and spread of infectious diseases [1]. Studies showed that SARS $\mathrm{CoV}$ is a stable virus that may potentially be transmitted by indirect contact or fomites,

\footnotetext{
* e-mail: yk1res@bolton.ac.uk
}

especially in air-conditioned environments [2]. It is also essential to notice that it has proved that piercing variation in ambient temperature is associated with an increased risk of SARS [3]. Nevertheless, it was recently believed that the Coronavirus, like other infectious diseases, is affected by temperature, and the high temperature during the summer season may lead to its elimination [4].

It is a new belief that high air pollution levels maybe is "one of the most important contributors" to deaths from COVID-19. For example, the level of nitrogen dioxide, a pollutant produced mainly through diesel vehicles linked to health damage, and particularly lung disease, due to long term exposure and experiences long-lasting respiratory strain, its capability to defend itself from infections is inadequate. It could result in death when people contract COVID-19 [5]. The Satellite data from NASA display that 


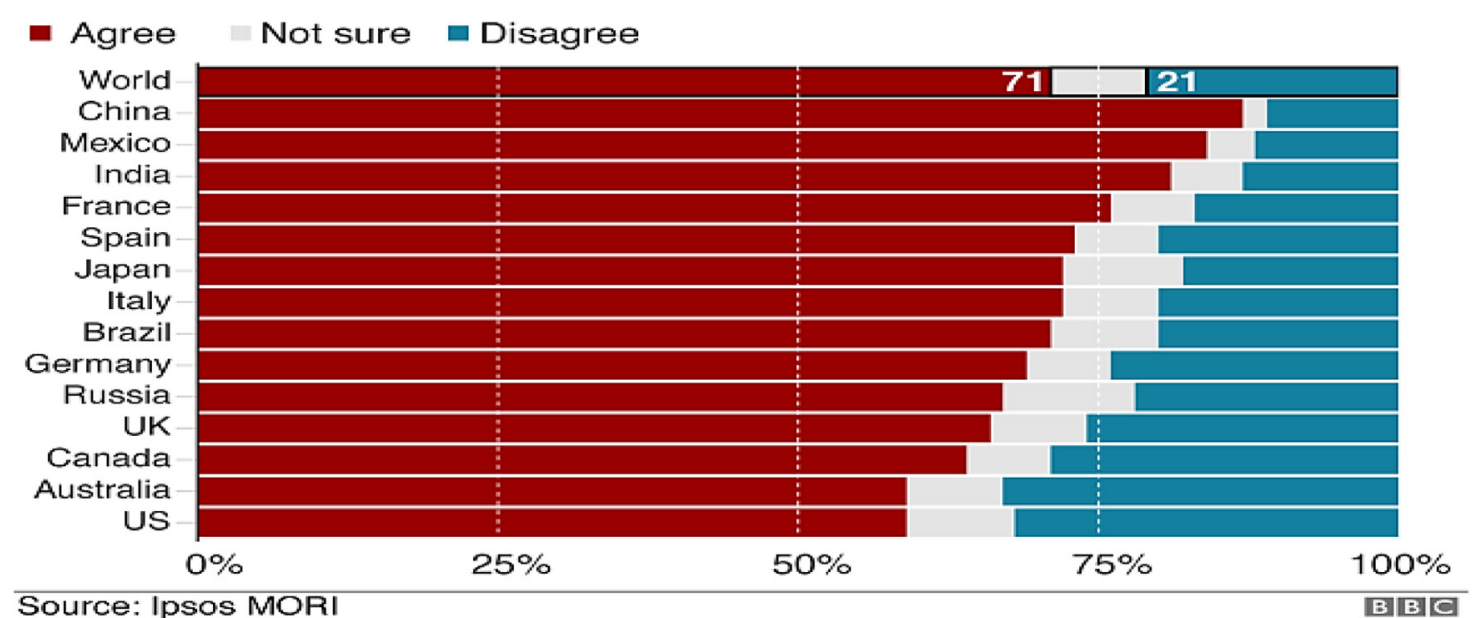

Fig. 1. Percentage of People who agree that, in the long term, climate change is as severe a crisis as COVID-19 [7].

minor traffic in the cities has led to pollution levels dropping worldwide. UAE and other counties in the Middle East have restriction to stay at their homes, reflecting on the reduced level of Nitrogen Dioxide $\mathrm{NO}_{2}$ a harmful pollutant [6]. People over the world have expressed their concern and thought that climate change is as severe as Coronavirus. Poll results show in Figure 1 [7]. This result put forward a demand to consider the large number of people to work from home after the pandemic ends.

The paper aims to assess air quality impacts in the Ajman Emirates during the lockdown when social distancing was implemented, and human activities were significantly eliminated. Moreover, it seeks to identify the percentages of the improved outdoor pollutants concentrations and the general air quality index.

\subsection{Worldwide air quality during COVID-19}

Several literature works have quoted that "the global response to the COVID-19 pandemic has resulted in unprecedented reductions in economic activity". It has been found that recording for meteorological variations, lockdown periods have reduced the population associated concentration of $\mathrm{NO}_{2}$ and PM levels between $60 \%$ and $31 \%$ in 34 countries, with mixed effects on Ozone. Reductions in transportation emissions are highly responsible for the $\mathrm{NO}_{2}$ anomalies [8]. It reports from several resources that a significant change and improvement noticed in the air quality over the world, as shown in Figure 2 [9].

\subsection{Short and long-term exposure to air pollution and COVID-19}

The geographical properties of COVID-19 infections with satellite and ground level for air quality index have been examined for different countries shows high infections when $\mathrm{PM}_{2.5}$ and $\mathrm{NO}_{2}$ had high levels [10]. A positive correlation between air quality and COVID-19 spread and mortality has been identified in different countries with the high-density population. However, less population density and size showed a negative correlation with the infections. For instance, in Germany, population density showed a weak connection with infections, while PM showed a weak negative correlation [11]. This is because of people's huge movement from large cities to the countryside, taking the virus with them [10]. Lin et al. [12], reported that higher ambient $\mathrm{CO}$ concentration was a risk factor for the increased spreading of COVID-19, while higher temperature, efficient ventilation and air pressure reduced its transmissibility. It has been suggested that $\mathrm{PM}_{10}$ may serve as a carrier for droplet nuclei, increasing the spread of COVID-19 [11]. Another study supported this result that showed an association between accelerate and vast diffusion of COVID-19 and air pollution [11]. Adhikari and Yin [13], shown that short-term exposures to meteorological factors such $\mathrm{O}_{3}$ could be related with COVID-19 transmission and initiation of the COVID-19. Still, disease aggravation and fatality depend on other factors [12]. A study collecting data from several cities in Italy for $\mathrm{PM}_{10}$ found that there exists a significant relationship between the $\mathrm{PM}_{10}$ exceedances and the initial spreading of COVID-19 [14]. It has been found through a new study in Europe should that $78 \%$ of the death occurred in five regions north Italy and central Spain as $\mathrm{NO}_{2}$ was at highest concentrations prevented the dispersion of air pollutants because of the combined with downward air pressure, [15]. Data collected from a significant number of municipalities in the Netherlands indicated that $\mathrm{PM}_{2.5}$ as a highly significant element of COVID-19 cases and hospital admissions [16]. Recent results published by Konstantinoudis et al., [17] showed that COVID-19 mortality rate increases by $0.5 \%$ for every $1 \mu \mathrm{g} / \mathrm{m} 3$ increase in $\mathrm{NO}_{2}$ and by $1.4 \%$ for every $1 \mu \mathrm{g} / \mathrm{m}^{3}$ increase in $\mathrm{PM}_{2 \cdot 5}$.

\subsection{Coronavirus crisis and the green recovery?}

The lockdown act imposed by the explored consequences from COVID-19 has minimised the industrial operations. The drop in traffic is a significant contributor to the fall in planet-warming $\mathrm{CO}_{2}$ emissions we have witnessed globally. Improved air quality, effective waste management, healthier water, and enhanced biodiversity protection will not only decrease the vulnerability of society to pandemics and improve resilience. Still, it will have the 

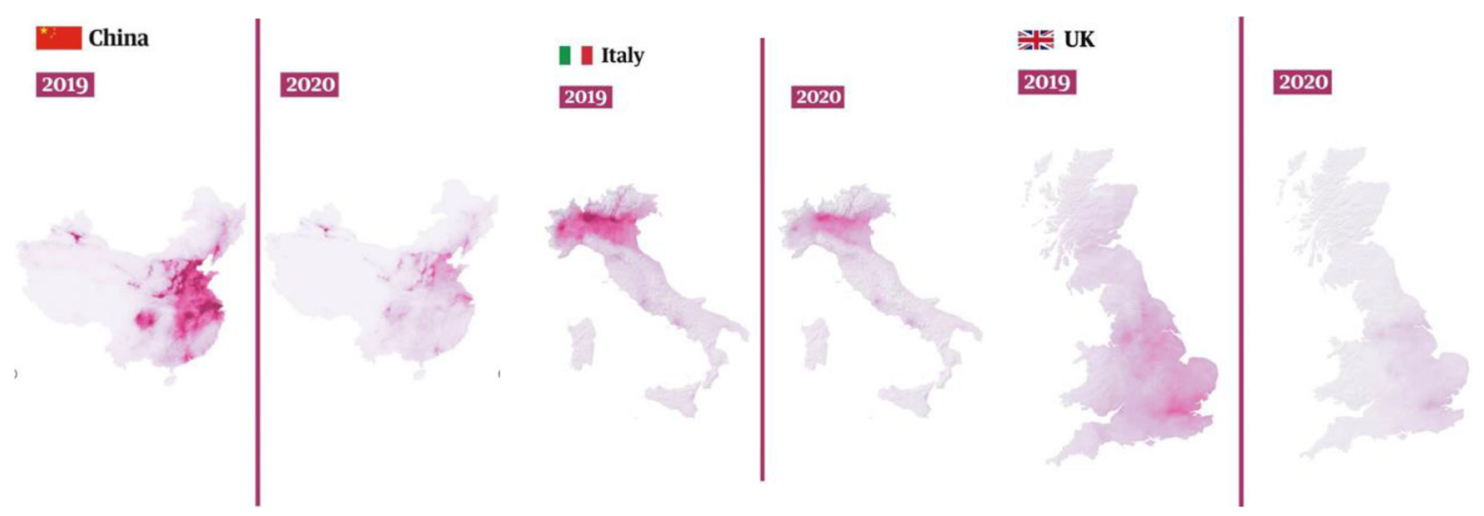

Fig. 2. Satellite photos for the level of air quality over the world [9].

potential to boost economic activity, create jobs, and generate income. Two choices are currently facing the Governments; the first is to bail out polluting businesses, using that as leverage to impose environmentally-minded reforms, or let them return to their carbon-intensive activities as an economical, quick fix [7]. It is an excellent opportunity to see evidence of climate change at this period to encourage the government to select the right choice to spur a green recovery. Measurements of the air pollution associated elements and analysis during the months over the lockdown time could lead to theoretical hypotheses and support further research to formulate the proper practices for a practical management model framework that can control future practices when the pandemic crisis ends. The UK has told environment ministers from 30 countries in an online conference to achieve progression in reducing greenhouse gas emissions that tackling climate change must be woven into the solution to the COVID-19 economic crisis [18]. The UK invests in technology and infostructure to sustainable power development, excluding industries with a high level of pollutions, restoring ecosystems on land and in the oceans, and supporting sustainable food, farming, and fishing.

\subsection{Primary air pollutant in the urban areas and their effects}

The following air quality parameters are monitored [19]:

- Sulfur dioxide

- Nitrogen dioxide

- Carbon monoxide

- Ozone

- $\mathrm{PM}_{10} \& \mathrm{PM}_{2.5}$

- Meteorological data

- Carbon Monoxide (CO): Carbon Monoxide is a highly toxic and unsafe pollutant, infamous for its lack of identifying colour and smell; sources of this gas most commonly, Carbon Monoxide formed by combustion engines running without modern catalytic converters, other conversant sources of carbon monoxide are old gas and fuel appliances, incinerators, and even cigarettes. The effects of carbon monoxide that it can have a profound impact on the environment as it is incredibly poisonous, and can contribute to hazardous ground-level air and ozone conditions.

- Ozone $\left(\mathrm{O}_{3}\right)$ : Ground-level Ozone has become a significant problem in recent years. The sources of Ground-level Ozone formed by chemical reactions between multiple different oxides found in the air when exposed to sunlight can form new compounds and leave Ozone as a byproduct. The majority of ozone emissions originated from the typical distrusts, such as car exhausts, factory processing, electric utilities and power plants, and chemical solvents. Ozone is a hazardous substance for most living organisms. As such, a rise in ground-level Ozone has a prominent effect on human health and the overall health of multiple ecosystems on land and in the seas.

- Nitrogen Dioxide $\left(\mathrm{NO}_{2}\right)$ : One of the oxides which can react to produce Ozone, Nitrogen Dioxide one of the gases that most commonly think to when considering air pollution, the Sources of Nitrogen Dioxide, like many other pollutants, record and released to the atmosphere as a result of burning of fuels in car engines, airplane engines, factories, and power plants. Effects of Nitrogen Dioxide that it tends to react with other agents to form nitric acid and other nitrates, paying to the formation of acid rain, Nitrogen Oxide has a significant effect on humans, increasing the probability of respiratory problems, cancers, and other lung problems. Nitrogen Dioxide's acid rains are incredibly damaging the plants and animals crosswise the world and lead to additional water systems problems.

- Sulfur Dioxide $\left(\mathrm{SO}_{2}\right)$ : a colourless, bad-smelling, toxic gas, is part of a larger group of chemicals referred to as sulfur oxides $\left(\mathrm{SO}_{\mathrm{x}}\right)$. These gases, especially $\mathrm{SO}_{2}$, are emitted by the burning of fossil fuels, oil, and diesel or other materials that contain sulfur, sulfur dioxide can create secondary pollutants once released into the air. Secondary pollutants formed with sulfur dioxide include sulfate aerosols, particulate matter, and acid rain. The gas sources are locomotives, ships, planes, and other equipment that still produce massive Sulfur Dioxide measurements. Industrial processes, mainly are extraction and purification, are also producers of the gas. The Effects of Sulfur Dioxide is a compound that often combinations with other pollutants in the air to form 
harmful acids, expected effects of Sulfur Dioxide poisoning are respiratory, eye problems, and even heart and circulatory problems.

- Particulate Matter (PM): Visible and tangible than the components listed above, but is no less dangerous or harmful. The particulate matter generally consists of soot, dirt, and chemical by-products produced through combustion or chemical compounds in another way it made by every single process involving chemicals and fuels - the innocuous processes of road creation. Any process which has a physical by-product will generally result in particulate matter. Particle Matter's effects can be exasperating to hazardous, often hampering roads' visibility and resulting in respiratory problems.

Table 1. Ambient air quality standard UAE [20].

\begin{tabular}{lll}
\hline Pollutant & $\begin{array}{l}\text { Averaging } \\
\text { period }\left(\mu \mathrm{g} / \mathrm{m}^{3}\right)(\mathrm{h})\end{array}$ & UAE standard $\left(\mu \mathrm{g} / \mathrm{m}^{3}\right)$ \\
\hline $\mathbf{S O}_{\mathbf{2}}$ & 1 & 350 \\
$\mathbf{N O}_{\mathbf{2}}$ & 24 & 150 \\
& 24 & 60 \\
$\mathbf{C O}$ & 1 & $30 \mathrm{mg} / \mathrm{Nm}^{3}$ \\
& 8 & $10 \mathrm{mg} / \mathrm{Nm}^{3}$ \\
$\mathbf{O}_{\mathbf{3}}$ & 1 & 200 \\
$\mathbf{P M}_{\mathbf{1 0}}$ & 8 & 120 \\
\hline
\end{tabular}

Particulate matter is related to a range of lung, heart, and eye conditions in humans and links to an increased likelihood of developing cancers later in life. Table 1 is illustrating the maximum acceptable limits according to the UAE standards [20].

\section{Materials and methods}

A network of environmental recording stations was constructed at different sites to cover the whole Emirate of Ajman. The stations' available equipment was intended to demonstrate real-time information about pollution levels at the strategic locations to record, analyse and evaluate the impacts of air pollution on the community and provide a continuous source of air quality data for further research, inspection and monitoring. Figure 3 shows a map of the Emirate of Ajman, pointing out the locations of the seven stations that have been initiated to collect the air quality data. The positions and coordinates of the selected stations are listed in Table 2. The stations continuously monitor and records the primary gases $\left(\mathrm{SO}_{2}, \mathrm{CO}, \mathrm{NO}_{2}\right.$, $\mathrm{PM}_{2.5}, \mathrm{PM}_{10}$, and $\left.\mathrm{O}_{3}\right)$ in addition to the weather parameter. The stations' location selected by conducting a dispersion modelling study leads to the concentration of various pollutants [21].

The instruments' methodology in the monitoring stations conforms to "reference methods" or "equivalent methods" according to the Environmental Protection Agency (EPA) guidelines to monitor targeted pollutants.

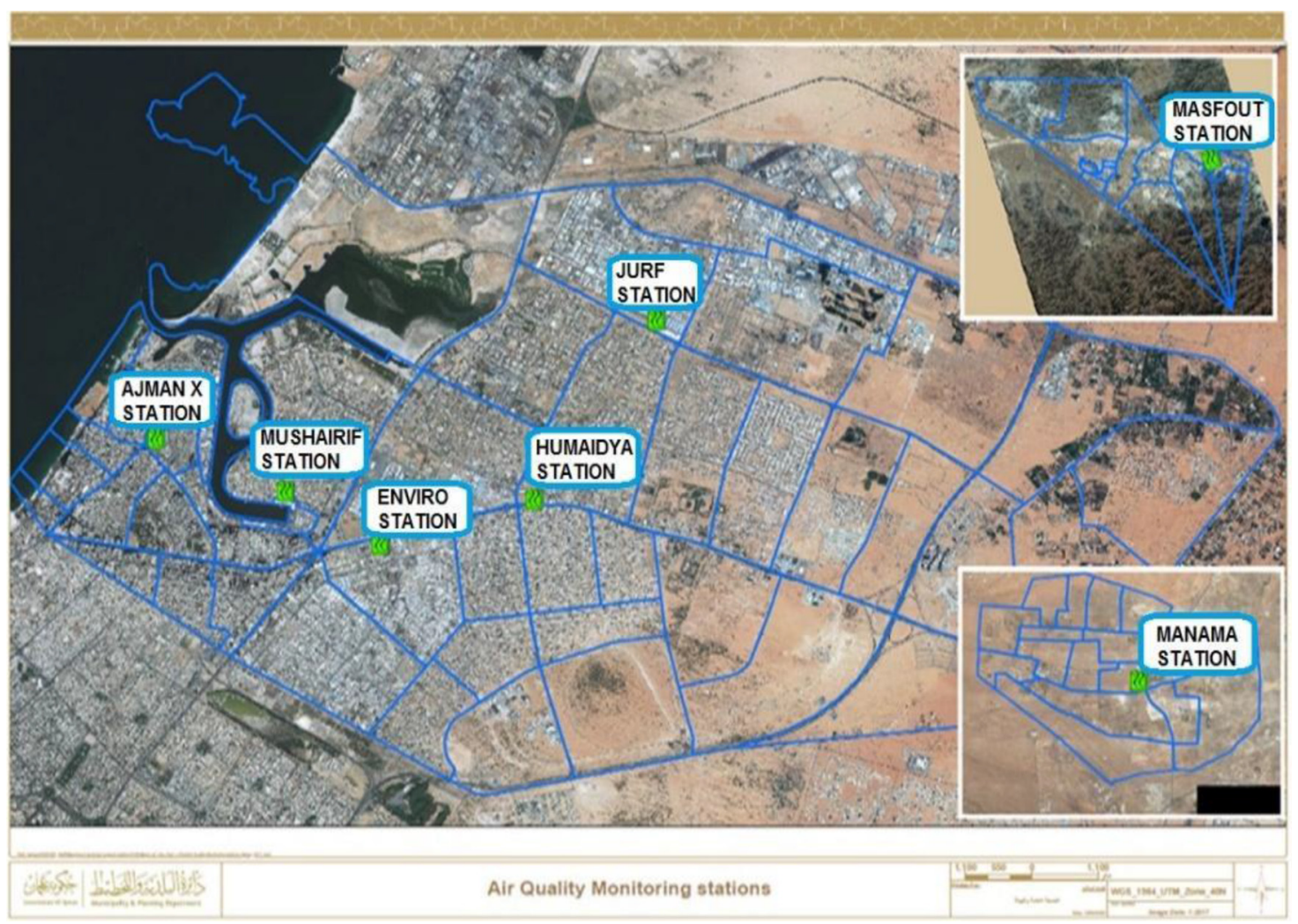

Fig. 3. The air quality stations' location [21]. 
Table 2. List of the selected environmental stations with the measured elements.

\begin{tabular}{|c|c|c|c|c|c|c|c|c|c|c|}
\hline Month & $\begin{array}{l}\mathrm{SO}_{2} \\
(24 \mathrm{hr})-2019\end{array}$ & $\begin{array}{l}\mathrm{SO}_{2} \\
(24 \mathrm{hr})-2020\end{array}$ & $\begin{array}{l}\mathrm{NO}_{2} \\
(24 \mathrm{hr})-2019\end{array}$ & $\begin{array}{l}\mathrm{NO}_{2} \\
(24 \mathrm{hr})-2020\end{array}$ & $\begin{array}{l}\text { CO } \\
(8 \mathrm{hr})-2019\end{array}$ & $\begin{array}{l}\mathrm{CO} \\
(8 \mathrm{hr})-2020\end{array}$ & $\begin{array}{l}\mathrm{O}_{3} \\
(8 \mathrm{hr})-2019\end{array}$ & $\begin{array}{l}\mathrm{O}_{3} \\
(8 \mathrm{hr})-2020\end{array}$ & $\begin{array}{l}\mathrm{PM}_{10} \\
(24 \mathrm{hr})-2019\end{array}$ & $\begin{array}{l}\mathrm{PM}_{10} \\
(24 \mathrm{hr})-2020\end{array}$ \\
\hline Jan & 4.51 & 3.79 & 17.22 & 15.01 & 0.42 & 0.55 & 24.52 & 29.56 & 57.11 & 25.97 \\
\hline Feb & 4.78 & 6.06 & 14.45 & 11.83 & 0.37 & 0.56 & 53.75 & 34.56 & 39.63 & 32.95 \\
\hline Mar & 4.41 & 1.15 & 16.67 & 8.14 & 0.44 & 0.31 & 61.95 & 39.72 & 41.44 & 29.28 \\
\hline Apr & 4.30 & 0.92 & 29.61 & 8.30 & 0.46 & 0.31 & 34.72 & 37.25 & 40.66 & 28.69 \\
\hline May & 7.64 & 3.13 & 27.96 & 6.98 & 0.48 & 0.40 & 38.54 & 43.76 & 50.43 & 31.29 \\
\hline Jun & 8.14 & 2.95 & 23.41 & 5.86 & 0.47 & 0.47 & 55.20 & 85.93 & 54.77 & 36.36 \\
\hline Jul & 5.59 & 3.07 & 37.16 & 57.00 & 0.36 & 0.51 & 96.67 & 61.95 & 49.62 & 69.05 \\
\hline Aug & 1.54 & 4.71 & 49.59 & 19.46 & 0.45 & 0.50 & 64.71 & 85.95 & 47.94 & 84.32 \\
\hline Sep & 1.48 & 3.48 & 22.72 & 23.28 & 0.43 & 0.65 & 69.54 & 63.48 & 48.32 & \\
\hline
\end{tabular}

The stations have the uncertainty of each analyser which manufacturer and certification body has released. The technique used for the monitoring is called Continuous Monitoring Methods, which are high-resolution methods that provide continuous records of contaminant levels. They are capable of operating over weeks or months. The system is with minimum operator involvement. There exists a remote communication with the central base at the municipality. They have a high degree of measurement accuracy and have recognition levels around one order of magnitude. These are the most expensive monitoring methods. A high standard of maintenance, operational, calibration, and quality control procedures required for good data quality Figure 4 shows the type of station used in the study [22].

In order to accumulate the COVID-19 correlated impacts on the air quality, data were collected through the Ajman Air Quality Monitoring Network [23] and after that analysed and compared between 2018 and 2020. Besides, identify the effect of the actions taken to avoid the spread of COVID-19 on the air quality in the Emirate of Ajman and the other Emirates within the UAE.

\section{Results and discussions}

Data was primarily collected from the associated stations for each gas and analysed to be suitably presented for discussion, comparing each gas amount at the same selected period and station. Figure 5 shows Concentrations for $\mathrm{SO}_{2}, \mathrm{NO}_{2}, \mathrm{CO}, \mathrm{O}_{3}, \mathrm{PM}_{2.5}$ and $\mathrm{PM}_{10}$ pollutant concentration in $\mu \mathrm{g} / \mathrm{m}^{3}$ and $\mathrm{CO}$ concentration in $\mathrm{mg} / \mathrm{m}^{3}$ at the period (January-December) (2019-2020) [24] collected and combined to show the air quality in Ajman - UAE. The data shows a $60 \%$ reduction in May 2020 on the $\mathrm{SO}_{2}$ concentration than the concentration for the same period of 2019. Also, a reduction in the $\mathrm{NO}_{2}$ was evident that the percentage reached $50 \%$ during the pandemic 2020. The figure shows CO pollutant concentration in the air during the appointed pandemic period with a $33 \%$ reduction. $\mathrm{PM}_{2.5}$ consistency within the air has had a significant change with a $40 \%$ reduction during the pandemic 2020, while $\mathrm{PM}_{10}$ concentration shows reduction with percentage reaches $12 \%$ during the pandemic $2020 . \mathrm{O}_{3}$ does not show an apparent decrease at that period. Approving this reduction, data for the year 2018 and detect if the trend was different from what has been indicated in Figure 5. For this purpose, Figure 6 shows data presented for a similar period for 2018 and 2019-2020, which clearly indicates a steep reduction over the three years and significantly reduced between 2019 and 2020 .

In order to have an overall compared view for the air quality elements Figure 7 shows all elements and their concentrations.

Data collected for all gases are summarised in Table 3. It can be seen that the most significant changes are evident during the months (February, March, April \& May) see Figures 5-7.

The results clearly show the decrease in all the pollutants in different percentages and during the periods of the day, which approve the theory that decreases in the pollutants' concentrations due to the reduction in the vehicle's movement and the reduction of the industrial activity part the restriction of coved-19. The action taken to stop the spread of COVID-19 has a direct impact on air quality. This result should be the alarm that the atmosphere can be improved by reducing human activities, using environmentally friendly vehicles, the cleaning industry, and going for essential needs. The analysis of the surface concentration of primary and secondary species measured at the monitoring stations operated in Ajman a vital transition in air pollution as one crosses the date of the lockdown imposed to UAE in response to the COVID-19 outbreak. The result was the decrease in the main gases and $\mathrm{PM}_{2.5}$ and $\mathrm{PM}_{10}$.

\subsection{Air quality index}

The Air Quality Index (AQI) is a dimensionless index that quantitatively describes air quality status. As indicated in Equation (1), the sub-AQI of the six criteria pollutants $\left(\mathrm{PM}_{2.5}, \mathrm{PM}_{10}, \mathrm{CO}, \mathrm{SO}_{2}, \mathrm{NO}_{2}\right.$, and $\left.\mathrm{O}_{3}\right)$ were first calculated with the observation concentrations. The AQI comes from the maximum of all pollutants' sub-AQI, as shown in Equation (2), where when the AQI is higher than 50, the contributor of the maximum sub-AQI is defined as 


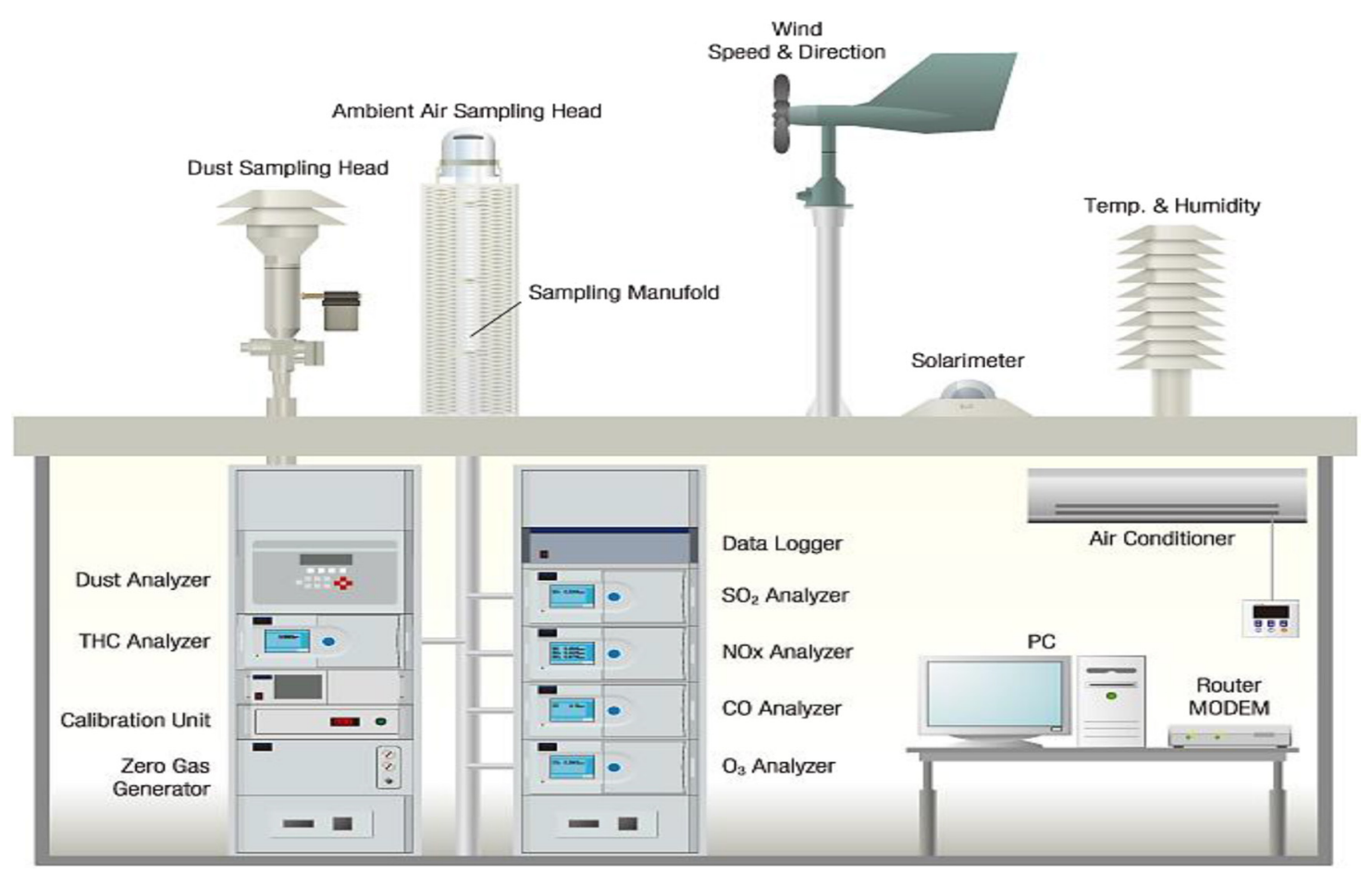

Fig. 4. Air quality station module [22].

Table 3. The average data comparison.

\begin{tabular}{lllllllllrrr}
\hline Month & $\begin{array}{l}\mathrm{SO}_{2} \\
(24 \mathrm{hr})-2019\end{array}$ & $\begin{array}{l}\mathrm{SO}_{2} \\
(24 \mathrm{hr})-2020\end{array}$ & $\begin{array}{l}\mathrm{NO}_{2} \\
(24 \mathrm{hr})-2019\end{array}$ & $\begin{array}{l}\mathrm{NO}_{2} \\
(24 \mathrm{hr})-2020\end{array}$ & $\begin{array}{l}\mathrm{CO} \\
(8 \mathrm{hr})-2019\end{array}$ & $\begin{array}{l}\mathrm{CO} \\
(8 \mathrm{hr})-2020\end{array}$ & $\begin{array}{l}\mathrm{O}_{3} \\
(8 \mathrm{hr})-2019\end{array}$ & $\begin{array}{l}\mathrm{O}_{3} \\
(8 \mathrm{hr})-2020\end{array}$ & $\begin{array}{l}\mathrm{PM}_{10} \\
(24 \mathrm{hr})-2019\end{array}$ \\
\hline Jan & 2.61 & 12.05 & 39.32 & 37.07 & 0.50 & 0.36 & 17.75 & 26.68 & 85.23 \\
Feb & 4.63 & 26.53 & 24.30 & 35.75 & 0.38 & 0.43 & 31.06 & 37.94 & 67.20 & 112.39 \\
Mar & 6.22 & 30.58 & 22.49 & 27.32 & 0.36 & 0.30 & 38.44 & 40.07 & 82.35 & 100.81 \\
Apr & 6.18 & 3.85 & 33.12 & 16.69 & 0.49 & 0.18 & 30.55 & 38.78 & 74.04 & 78.67 \\
May & 7.49 & 6.22 & 43.75 & 17.29 & 0.56 & 0.16 & 43.02 & 65.00 & 97.20 & 97.82 \\
Jun & 9.13 & 10.06 & 43.66 & 15.30 & 0.73 & 0.32 & 56.98 & 96.27 & 102.00 & 294.98 \\
Jul & 8.65 & 13.52 & 29.51 & 10.60 & 0.37 & 0.29 & 95.48 & 67.83 & 95.45 & 223.06 \\
Aug & 7.29 & 9.14 & 31.88 & 7.95 & 0.30 & 0.27 & 86.64 & 54.66 & 91.71 & 142.39 \\
Sep & 5.85 & 3.90 & 28.45 & 20.70 & 0.33 & 0.48 & 77.66 & 22.72 & 99.15 & 138.06 \\
\hline
\end{tabular}

the primary pollutant on that day $[25,26]$ and presented by $\mathrm{Xu}$ et al. [27]. The Air Quality Index can be derived as follows:

$$
\begin{gathered}
\mathbf{I A Q I p}=\frac{I_{\text {high }}-I_{\text {low }}}{C_{\text {high }}-C_{\text {low }}}\left(C_{P}-C_{\text {low }}\right)+I_{\text {low }} \\
\mathbf{A Q I}=\max \left(I_{1}, I_{2}, \ldots, I_{n}\right)
\end{gathered}
$$

$\boldsymbol{I A} \boldsymbol{Q I p}$ : the air quality sub-index for air pollution $\mathrm{p}$.

$\mathrm{Cp}$ : the concentration of pollutants $\mathrm{p}$.

$C_{\text {low }}$ : the concentration breakpoint that is $\leq \mathrm{C}_{\mathrm{p}}$.

$C_{\text {high }}$ : the concentration breakpoint that is $\geq \mathrm{C}_{\mathrm{p}}$.

$I_{\text {low: }}$ : the index breakpoint corresponding to $\mathrm{C}_{\text {low. }}$.

$I_{h i g h:}$ the index breakpoint corresponding to $\mathrm{C}_{\text {high. }}$.

The daily AQIs are typically calculated based on the 24-h average concentration of $\mathrm{PM}_{2.5}, \mathrm{PM}_{10}, \mathrm{CO}, \mathrm{SO}_{2}$,
$\mathrm{NO}_{2}$, and the daily average 8-hours maximum concentration of $\mathrm{O}_{3}$ [28]. According to the United State Environment Protection Agency (USEPA) AQI, the range of AQI values can be classified, as shown in Figure 8 [29]. Colours classes are representing the numbers, as shown in Table 4.

Considering the results discussed earlier in Figures 5-7 and from the air quality index formula Equation (1), Figure 9, represents the air quality index calculated and compared for 2018, 2019 and 2020.

\subsection{Implications}

It is impractical to reduce economic activity to equivalent levels to lockdown and maintain business and industrial activities as usual, as it worsens pollutant emissions. This article has demonstrated reductions in many air quality 
Comparision SO2 pollutants concentration in breathing air between 2019 and 2020

$\square$ SO2 (24hr)-2019 —SO2 (24hr)-2020

-Reducing Trend

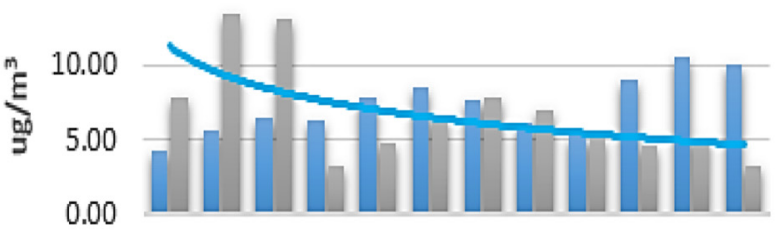

Jan Feb Mar Apr May Jun Jul Aug Sep Oct Nov Dec

Comparision $\mathrm{CO}$ pollutants concentration in

breathing air between 2019 and 2020

$\square \mathrm{CO}(8 \mathrm{hr})-2019 \square \mathrm{CO}(8 \mathrm{hr})-2020 \simeq$ Reducing Trend

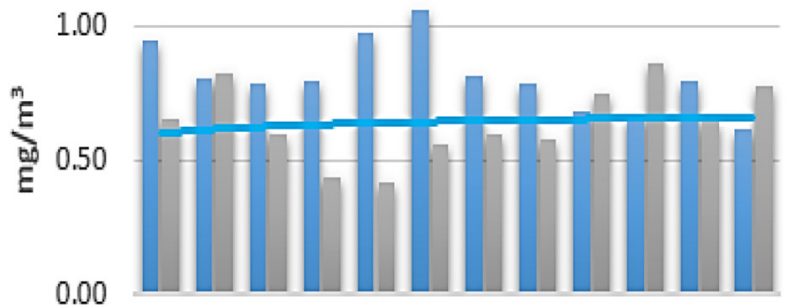

Jan Feb Mar Apr May Jun Jul Aug Sep Oct Nov Dec

Comparision PM2.5 pollutants concentration in breathing air between 2019 and 2020

$\square$ PM2.5 (24hr)-2019 — PM2.5 (24hr)-2020

- Normal Trend

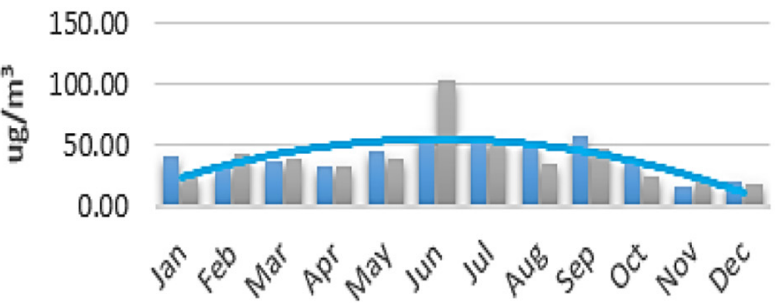

Comparision NO2 pollutants concentration in breathing air between 2019 and 2020

NO2 (24hr)-2019 NO2 (24hr)-2020

Reducing Trend

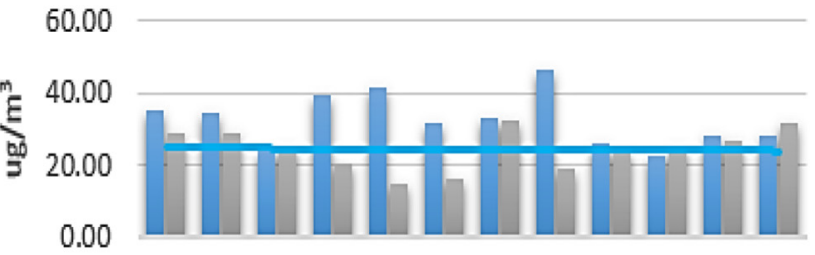

Jan Feb Mar Apr May Jun Jul Aug Sep Oct Nov Dec

Comparision 03 pollutants concentration in breathing air between 2019 and 2020

$\square 03(8 \mathrm{hr})-2019 \square 03(8 \mathrm{hr})-2020 \_$Reducing Trend

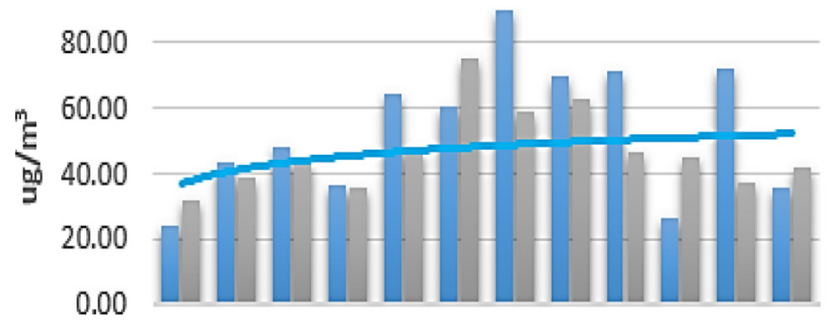

Jan Feb Mar Apr May Jun Jul Aug Sep Oct Nov Dec

\section{Comparision PM10 pollutants concentration in} breathing air between 2019 and 2020

$\square$ PM10 (24hr)-2019 —PM10 (24hr)-2020

—Reducing Trend

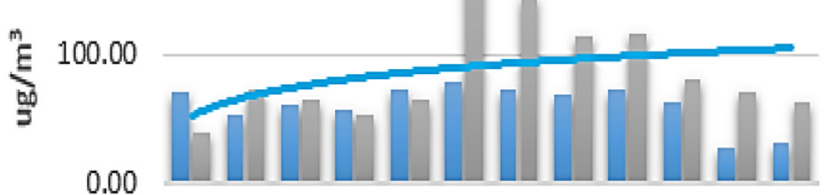

Jan Feb Mar Apr May Jun Jul Aug Sep Oct Nov Dec

Fig. 5. Air quality data collected for the period between 2019-2020 [24] (see Supplementary Files). 

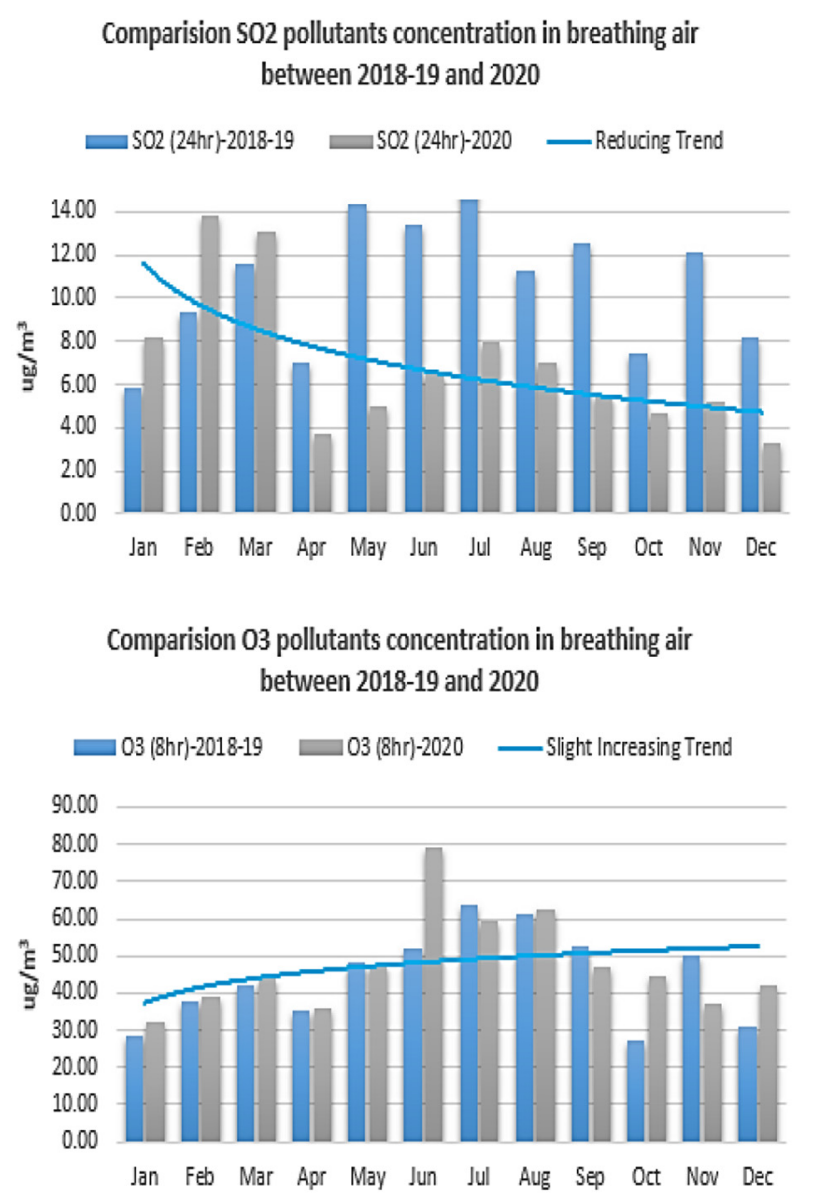
Comparision PM10 pollutants concentration in breathing air between 2018-19 and 2020

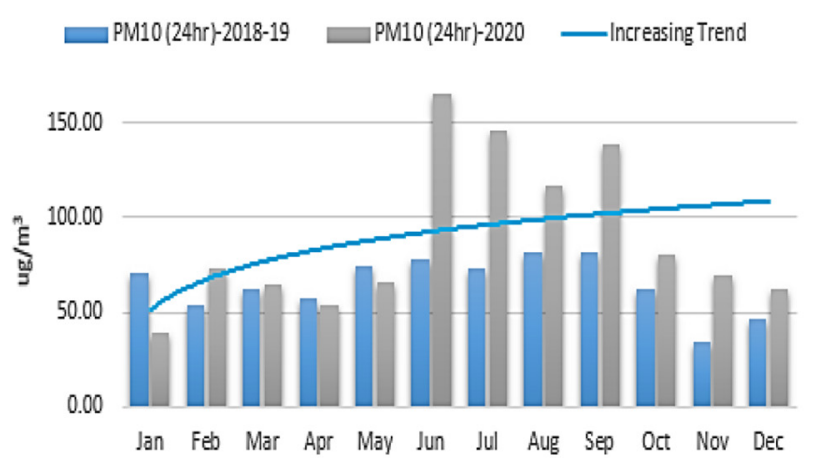

Comparision N02 pollutants concentration in breathing air between 2018-19 and 2020

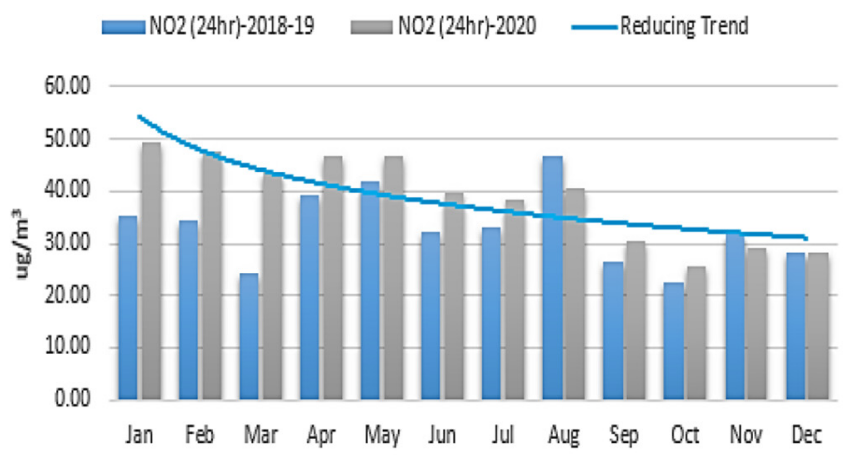

Comparision CO pollutants concentration in breathing air between 2018-19 and 2020

$=\mathrm{CO}(8 \mathrm{hr})-2018-19 \simeq \mathrm{CO}(8 \mathrm{hr})-2020 \longrightarrow$ Normal Trend

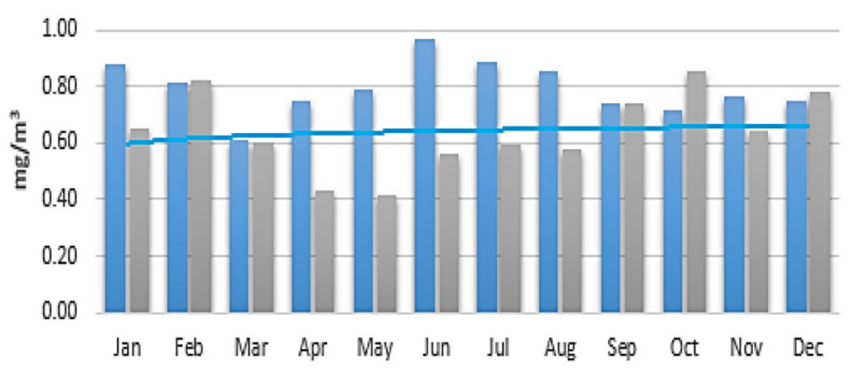

Comparision PM2.5 pollutants concentration in breathing air between 2018-19 and 2020

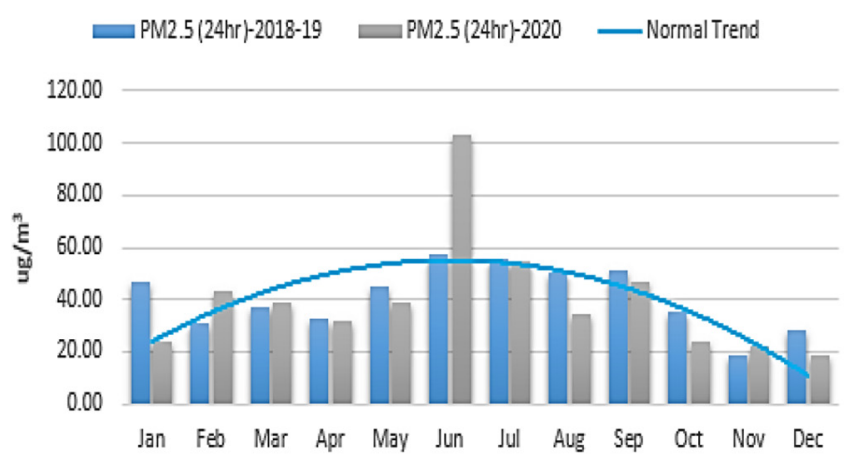

Fig. 6. Air quality data collected for the period between 2018-2020 [24] (see Supplementary Files).

interrelated elements such as $\mathrm{NO}_{2}$ and $\mathrm{PM}_{2.5}$ with mixed effect on $\mathrm{O}_{3}$ concentrations. COVID-19 deaths have been offset by the decrease of pollutants [30-32]. Household (indoor) air pollution from solid fuel use may have been increased due to the lockdown [33]. It is clear from the results that the present research work has recorded showed a reduction in the concentration of $\mathrm{NO}_{2}$, which is a consequence of the reduced number of operating vehicle transport. Therefore, it is recommended that the local authorities seriously look to the possibility of decreasing vehicles' use and work towards introducing initiatives to promote public transport systems and pedestrian and cycling activity. It is essential at this stage to learn from the lessons experienced due to the pandemic to encourage finding economically and socially sustainable alternatives to fossil fuel use in industries, transportation, and power plants, and cleaner fuels for use in households [34,35].

Moreover, evidence gathered in the literature has shown the rise and rise of the renewable city is thus to be expected as demand is likely to continue to rise for the urban living advantages associated with renewable city technologies and structures [36]. Emissions (greenhouse 


\section{Monthly Comparision of pollutants concentration in breathing air between 2019 and 2020}

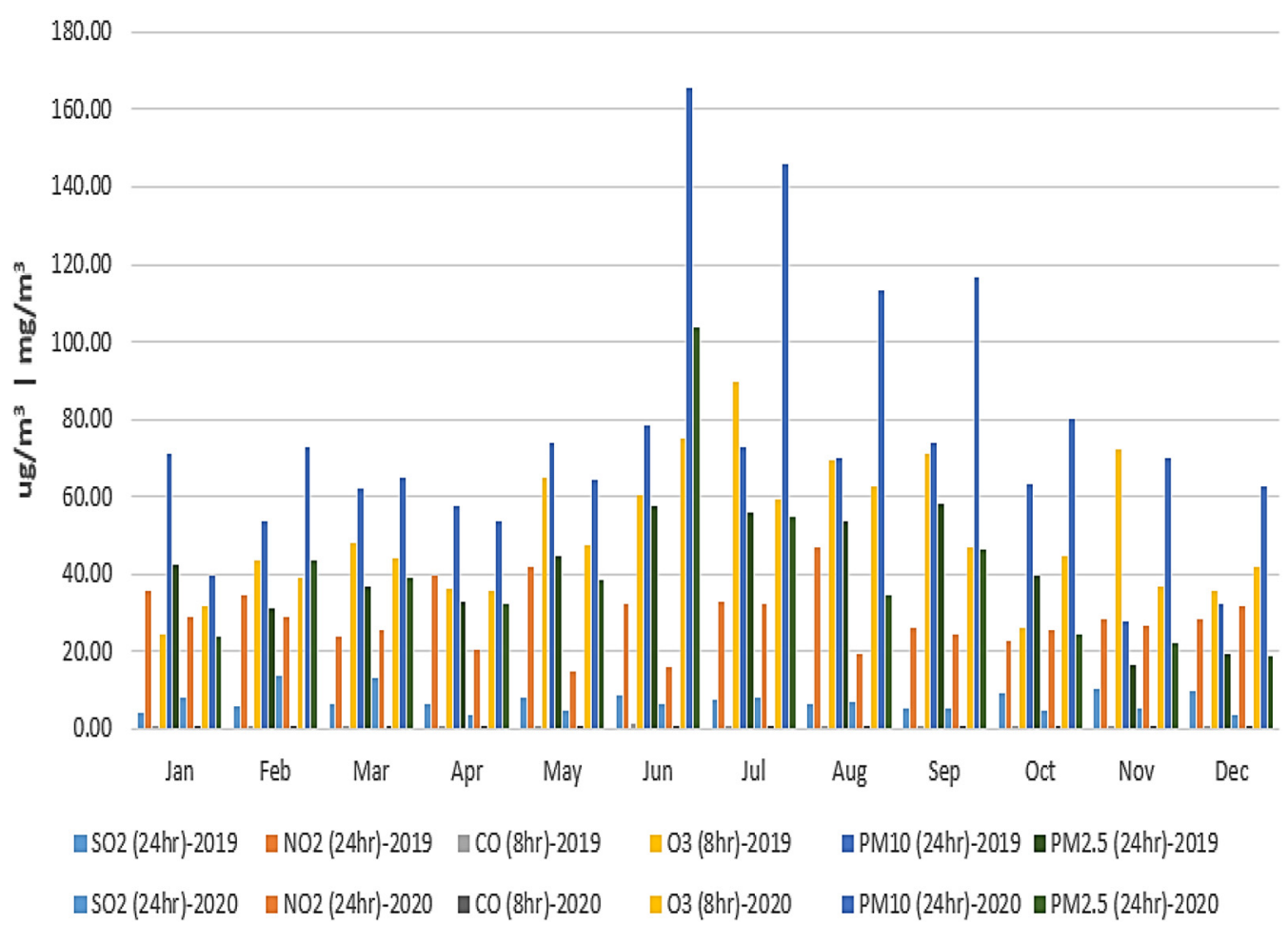

Fig. 7. Concentration of all elements of air quality compared between 2019 and 2020 [24] (see Supplementary Files).

gases like carbon dioxide, other air pollutants such as sulfur oxides and nitrogen, etc.) and waste (radioactive waste from coal-/oil burning power plants and nuclear energy, waste produced by factories, etc.) made by such resources harm the environment [37]. Therefore, The use of renewable energy, such as solar energy, will also reduce usiong fossil fuel and reduce the associated air pollution. Outdoor pollution has also been practically studied and considered in many developing countries that concluded similar effects of pollutants and found that concentrations of Volatile organic compounds (VOC) and NOx were high, making the studied area vulnerable to the risk of smog formation [38]. Governments in those countries must take immediate action. The UAE took significant steps to execute the convention on renewable energies. A costly vision with actual activities was comprised achieve full understanding of sensitivity to climate change and took anticipated steps to increase the investment in alternative sustainability to limit greenhouse gases (GHG) emissions [39].

\subsection{Indoor air quality}

From the previous section, it is recommended that a proper control to COVID-19 airborne transmission indoors following facilities are to be used [40]:

- Use of evaporative humidifiers, especially in cold, dry, and low direct sunlight conditions.

- To ensure further protection against viral aerosol particles, use efficient portable air cleaners with adequate mechanical ventilation.

- $\mathrm{CO}_{2}$ monitors should be used for checking $\mathrm{CO}_{2}$ workers and patients in the hospital rooms.

- Both aerosolised procedures using nebulisers during medical procedures and hydrogen peroxide disinfectants for indoor cleaning should be avoided.

- The UV-C technique should not be used too often to avoid increases in the toxic gas ozone concentration.

Systems were proposed to minimise the airborne transmission of the infectious disease caused by airconditioning and heating systems. One of the promising ideas discussed by Korichi et al. [41] proved efficient to provide clean heating for confined enclosed spaces. Radiator panel heating system is an effective solution to improve indoor climate and the coefficient of performance of the geothermal heat pump simultaneously. This is to be implemented in hospitals and other residential and public spaces and can reduce transmission of COVID-19 and other airborne infectious diseases if implemented on a large scale. 


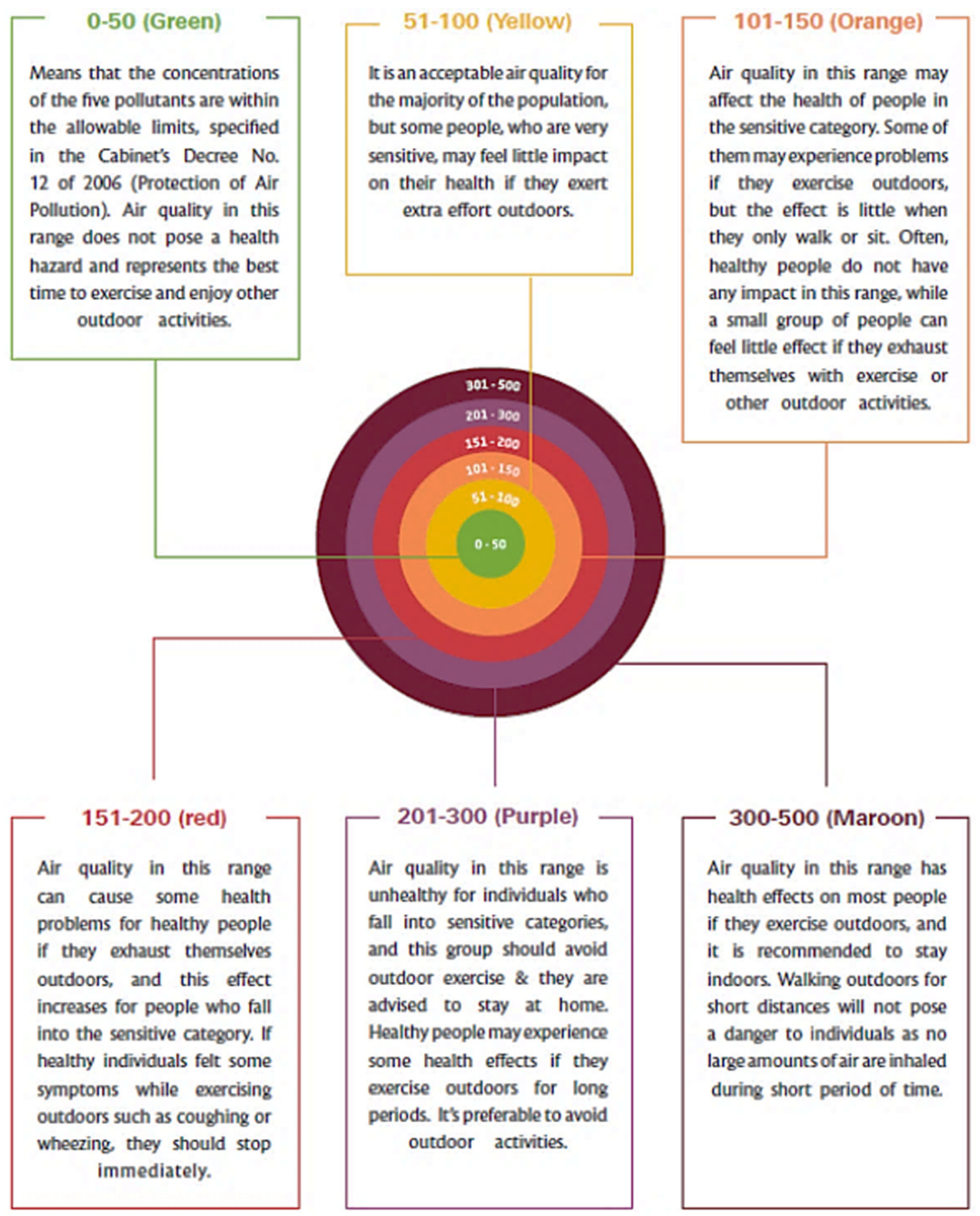

Fig. 8. AQI values description adapted by UAE.

\section{Conclusions}

The paper shows that it was clear that the air quality was improved during the pandemic as during that period there was a reduction in most of the human activity, as per that results in its possible to reduces the air pollution if we change our behaviour and activities, through the public transport, the electric vehicles and glean industries. The lockdown during (COVID-19) has caused an extraordinary decline in global economic, wellbeing and transport movement. Seven environmental air stations in the
Emirate of Ajman and the surrounding were used to collect data which shows effects of meteorological variability and found declines in the populationweighted concentration of ground-level nitrogen dioxide $\left(\mathrm{NO}_{2}: 40-60 \%\right)$ and inhaled particulate matter $\left(\mathrm{PM}_{2.5}: 40 \%\right),\left(\mathrm{PM}_{10}: 12 \%\right)$ and $\mathrm{CO}$ concentrations. When the pandemic rules were introduced, they significantly reduced human movements, particularly in the road transport and civil aviation sectors. This effect has similar consequences when the industrial activities were slowed down mainly at night. However, the article has found that 
Table 4. Colours and classes for AQI - UAE.

\begin{tabular}{lllllllll}
\hline Month & $\begin{array}{l}\mathrm{SO}_{2} \\
(24 \mathrm{hr})-2019\end{array}$ & $\begin{array}{l}\mathrm{SO}_{2} \\
(24 \mathrm{hr})-2020\end{array}$ & $\begin{array}{l}\mathrm{NO}_{2} \\
(24 \mathrm{hr})-2019\end{array}$ & $\begin{array}{l}\mathrm{NO}_{2} \\
(24 \mathrm{hr})-2020\end{array}$ & $\begin{array}{l}\mathrm{CO} \\
(8 \mathrm{hr})-2019\end{array}$ & $\begin{array}{l}\mathrm{CO} \\
(8 \mathrm{hr})-2020\end{array}$ & $\begin{array}{l}\mathrm{O}_{3} \\
(8 \mathrm{hr})-2019\end{array}$ & $\begin{array}{l}\mathrm{O}_{3} \\
(8 \mathrm{hr})-2020\end{array}$ \\
\hline Jan & 6.03 & 7.71 & 49.85 & 34.21 & 1.92 & 1.05 & 30.34 & 39.22 \\
$\mathrm{Feb}$ & 7.42 & 7.92 & 64.71 & 38.69 & 1.66 & 1.50 & 45.63 & 44.75 \\
Mar & 8.80 & 7.44 & 33.05 & 40.86 & 1.58 & 1.20 & 43.38 & 51.57 \\
Apr & 8.66 & 5.29 & 55.47 & 36.09 & 1.44 & 0.81 & 43.49 & 31.02 \\
May & 8.40 & 5.24 & 54.22 & 20.44 & 1.88 & 0.69 & 112.53 & 33.90 \\
Jun & 8.50 & 6.50 & 29.14 & 27.10 & 1.98 & 0.89 & 68.22 & 43.38 \\
Jul & 8.78 & 7.19 & 32.05 & 29.81 & 1.73 & 0.98 & 76.79 & 47.62 \\
Aug & 9.63 & 7.11 & 59.12 & 29.91 & 1.62 & 0.97 & 57.43 & 47.31 \\
Sep & 8.64 & 7.86 & 27.68 & 28.73 & 1.30 & 1.10 & 66.05 & 54.33 \\
\hline
\end{tabular}

\section{Air Quality Index}

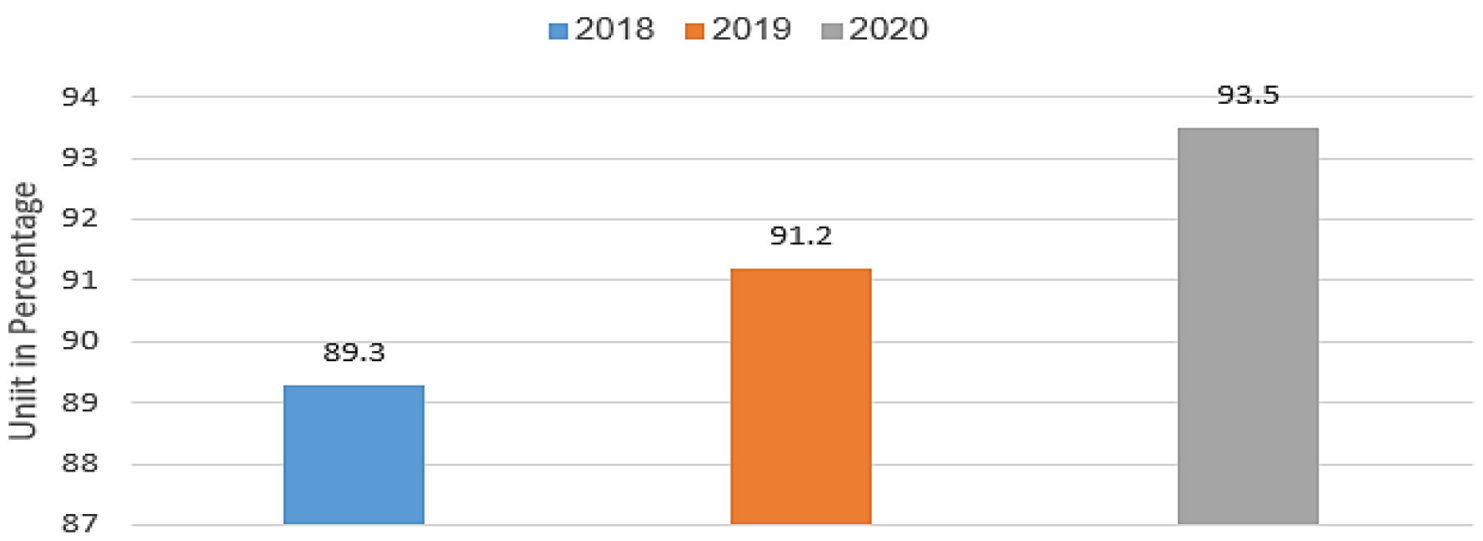

Fig. 9. Air quality index calculated and compared for 2018, 2019 and 2020.

the transmission of infectious diseases such as COVID-19 has been increased in many aspects that have the human contained in an indoor environment without considering the proper ventilation and air filtration. In this case, the air quality has worsened, and the air quality elements supported the transmission of the disease through the air particles rather than from human to human, for example, in care houses and hospitals. Therefore the present research has introduced some recommended practices to overcome such a hazardous issue.

\section{Supplementary Material}

The Supplementary Material is available at https://doi. org $/ 10.1051 /$ rees $/ 2021010 /$ olm.

\section{References}

1. F. Beugnet, K. Chalvet-Monfray, Impact of climate change in the epidemiology of vector-borne diseases in domestic carnivores, Comp. Immunol. Microbiol. Infect. Dis. 36, 559-566 (2013)
2. K. Chan, J. Peiris, S. Lam, L. Poon, K. Yuen, W. Seto, The effects of temperature and relative humidity on the viability of the SARS coronavirus, Adv. Virol. 2011, 1-7 (2011)

3. Y. Yao, J. Pan, Z. Liu, X. Meng, W. Wang, H. Kan, W. Wang, No association of COVID-19 transmission with temperature or UV radiation in Chinese cities, Eur. Respir. J. 55, 2000517 (2020)

4. M. Page, Will The COVID-19 Coronavirus Outbreak Die Out In The Summer's Heat? New Scientist, 2020. https:// www.newscientist.com/article/2233249-will-the-covid-19-co ronavirus-outbreak-die-out-in-the-summers-heat (accessed May 10, 2020)

5. D. Carrington, Air Pollution May Be' Key Contributor' To COVID-19 Deaths - Study. the Guardian, 2020. https:// www.theguardian.com/environment/2020/apr/20/air-pollu tion-may-be-key-contributor-to-covid-19-deaths-study (Accessed May 10, 2020)

6. Curly Tales, COVID-19: \#Stayhome Measure Improves Air Quality In UAE|Curly Tales, 2020. https://curlytales.com/ covid-19-in-uae-stayathome-improves-air-quality-in-uae/ (accessed May 10, 2020)

7. BBC News, Can Coronavirus Crisis Spur A Green Recovery?, 2020. https://www.bbc.co.uk/news/science-environment52488134 (accessed May 11, 2020) 
8. Z.S. Venter, K. Aunan, S. Chowdhury, J. Lelieveld, COVID-19 lockdowns cause global air pollution declines, Proc Natl Acad Sci U S A 117, 18984 (2020)

9. J. Watts, N. Kommenda, Coronavirus pandemic leading to huge drop in air pollution, 2020. https://www.theguardian. com/environment/2020/mar/23/coronavirus-pandemicleading-to-huge-drop-in-air-pollution (accessed November 21, 2020)

10. R. Pansini, D. Fornacca, Higher virulence of COVID-19 in the air-polluted regions of eight severely affected countries, Epidemiology (2020)

11. N. Ali, F. Islam, The effects of air pollution on COVID-19 infection and mortality - a review on recent evidence, Front. Public Health 8, 779 (2020)

12. S. Lin, D. Wei, Y. Sun, K. Chen, L. Yang, B. Liu et al., Region-specific air pollutants and meteorological parameters influence COVID-19: a study from mainland China, Ecotoxicol. Environ. Safety, 204 (2020)

13. A. Adhikari, J. Yin, Short-term effects of ambient Ozone, $\mathrm{PM}_{2.5}$, and meteorological factors on COVID-19 confirmed cases and deaths in Queens, New York, Int J Environ Res Public Health (2020)

14. L. Setti, F. Passarini, G. De Gennaro, P. Barbieri, M.G. Perrone, A. Piazzalunga, The potential role of particulate matter in the spreading of COVID-19 in Northern Italy: first evidence-based research hypotheses, Public Glob. Health 10, e039338 (2020)

15. Y. Ogen, Assessing nitrogen dioxide $\left(\mathrm{NO}_{2}\right)$ levels as a contributing factor to coronavirus (COVID-19) fatality, Sci. Total Environ. (2020)

16. B.P.J. Andree, Incidence of COVID-19 and connections with air pollution exposure: evidence from the Netherlands, Epidemiology (2020)

17. G. Konstantinoudis, T. Padellini, J.E. Bennett, B. Davies, M. Ezzati, M. Blangiardo, Long-term exposure to airpollution and COVID-19 mortality in England: a hierarchical spatial analysis, Public Glob. Health 150, 106422 (2020)

18. R. Harrabin, Covid Recovery Plan 'Must Tackle Climate Change', 2020. https://www.bbc.co.uk/news/science-envi ronment-52418624 (accessed May 11, 2020)

19. AMPD, Environmental Key Performance Indicator Review, 2021. Ajman Municipality and Planning Department. Data request by officiual communications

20. UAE federal law, On the Protection and Development of the Environment, 1999, s.l.: UAE Ministry of Climate Change and Environment

21. GISDEPT, Air Quality Data Stations in The Emirate of Ajman, 2018. GIS Department, Ajman Municipality and Planning Department. Data request by officiual communications

22. HORIBA. Air Quality Monitoring System, 2020. https:// www.horiba.com/en_en/products/detail/action/show/Prod uct/aqms-1560/ (accessed September 21, 2020)

23. Municipality \& Planning Department, City of Ajman Population and Waste management, 2020 Ajman: Municipality \& Planning Department. (Data requested by official communications)
24. AMPD, Air Quality Data (2019-2020), 2020. Ajman Municipality and Planning Department. Data request by officiual communications

25. Q. She, X. Peng, Q. Xu, L. Long, N. Wei, M. Liu, W. Jia, T. Zhou, J. Han, W. Xiang, Air quality and its response to satellite-derived urban form in the Yangtze river Delta, China, Ecol. Indic. 36, 297-306 (2017)

26. F.Z. Shen, X.L. Ge, J.L. Hu, D.Y. Nie, L. Tian, M.D. Chen, Air pollution characteristics and health risks in Henan Province, China, Environ. Res. Sci. 36, 625-634 (2017)

27. K. Xu, K. Cui, L. Young, Y. Wang, Y. Hsieh, S. Wan, J. Zhang, Air quality index, indicatory air pollutants and impact of COVID-19 event on the air quality near Central China, Aerosol Air Qual Res 20, 1204-1221 (2020)

28. R. Zhao, K.P. Cui, W.W. Wang, L.C. Wang, P. Yan, Atmospheric $\mathrm{PM}_{2.5}$ and total PCDD/Fs-WHO2005-TEQ level: case of Handan and Kaifeng cities, China, Aerosol Air Qual. Res. 36, 994-1007 (2018)

29. Moccae. UAE Air Quality Index Manual, Dubai, 2021. Ministry of Climate Change \& Environment - UAE

30. K. Chen, M. Wang, C. Huang, P.L. Kinney, P.T. Anastas, Air pollution reduction and mortality benefit during the COVID-19 outbreak in China, Lancet Planet. Health 4, e210-e212 (2020)

31. E. Conticini, B. Frediani, D. Caro, Can atmospheric pollution be considered a co-factor in extremely high level of SARS-CoV-2 lethality in Northern Italy? Environ. Pollut. 261, 114465 (2020)

32. X. Wu, R.C. Nethery, B.M. Sabath, D. Braun, F. Dominici, Exposure to air pollution and COVID-19 mortality in the United States, 2020. medRxiv:04.05.20054502

33. H. Shen, G. Shen, Y. Chen, G.R. Armistead, Y. Hu, X. Duan, W. Meng, Y. Xu, X. Yun, B. Lyu, S. Zhao, A. Hakami, J. Guo, S. Tao, K.R. Smith, Increased air pollution exposure among the Chinese population during the national quarantine in 2020, 2020. Earth ArXiv:10.31223/osf.io/ $6 \mathrm{~d} 9 \mathrm{rn}$

34. J. Lelieveld, K. Klingmüller, A. Pozzer, R.T. Burnett, A. Haines, V. Ramanathan, Effects of fossil fuel and total anthropogenic emission removal on public health and climate, Proc Natl Acad Sci U S A, 116, 7192-7197 (2019)

35. S. Chowdhury, S. Dey, S. Guttikunda, A. Pillarisetti, K.R. Smith, L. Di Girolamo, Indian annual ambient air quality standard is achievable by completely mitigating emissions from household sources, Proc Natl Acad Sci U S A 116, 10711-10716 (2019)

36. P. Newman, The rise and rise of renewable cities, Renew. Energy Environ. Sustain. 2, 10 (2017)

37. M.T. Chaichan, H.A. Kazem, Generating electricity using photovoltaic solar plants in Iraq, 2018. https://search. ebscohost.com/login.aspx?direct $=$ true\&scope $=$ site $\& \mathrm{db}=$ nlebk\&db $=$ nlabk\&AN $=1799002$

38. M.T. Chaichan, M.T. Chaichan, H.A. Kazem, H.A. Kazem, T.A. Abed, T.A. Abed, Traffic and outdoor air pollution levels near highways in Baghdad, Iraq, Environ. Dev. Sustai. 36, 589-603 (2018) 
39. H.M.S. Al-Maamary, H.A. Kazem, M.T. Chaichan, Climate change: the game changer in the Gulf Cooperation Council Region, Renew. Sustain. Energy Rev. 36, 555-576 (2017)

40. A. Ahlawat, S.K. Mishra, J.W. Birks, F. Costabile, A. Wiedensohler, Preventing airborne transmission of SARS-CoV-2 in hospitals and nursing homes, Int. J. Environ. Res. Public Health 17, 8553 (2020)
41. S. Korichi, B. Bouchekima, N. Naili, M. Azzouzi, The thermal behavior of a novel wall radiator panel coupled with horizontal ground source heat pump heating system: improve indoor environment to reduce the airborne transmission of infectious diseases, Renew. Energy Environ. Sustain. 5, 11 (2020)

Cite this article as: Yaser Omar Kaied, Abdul Salam K. Darwish, Peter Farrell, COVID-19 impact on air quality and associated elements: knowledge data of the Emirate of Ajman - UAE, Renew. Energy Environ. Sustain. 6, 15 (2021) 